\title{
Looking beyond the mountain: dispersal barriers in a changing world
}

Paul Caplat $^{1 *}$, Pim Edelaar ${ }^{2}$, Rachael Y Dudaniec ${ }^{3}$, Andy J Green ${ }^{4}$, Beth Okamura ${ }^{5}$ Julien Cote ${ }^{6,7}$ Johan Ekroos $^{1 \dagger}$, Per R Jonsson ${ }^{8 \dagger}$, Jakob Löndahl ${ }^{9 \dagger}$, Sylvie VM Tesson ${ }^{10 \dagger}$, and Eric J Petit ${ }^{11}$

Dispersal barriers have demographic, evolutionary, and ecosystem-wide consequences. With ongoing changes in the environment, some dispersal barriers will likely disappear while new ones will appear, and it is crucial to understand these dynamics to forecast species' distributions and adaptive potential. Here we review recent literature on the ecological and evolutionary aspects of dispersal to highlight key dynamics of dispersal barriers in the face of global change. After defining dispersal barriers, we explain that a better understanding of their dynamics requires identifying the barrier types that are most susceptible to change and predicting species' responses. This knowledge is a prerequisite for designing management strategies to increase or reduce connectivity, and maintain adaptive potential. Our intent is to motivate researchers to explicitly consider dispersal barriers in order to better forecast the dynamics of species and ecosystems subject to global change.

Front Ecol Environ 2016; 14(5): 261-268, doi:10.1002/fee.1280

$E_{\mathrm{d}}^{\mathrm{n}}$ nvironmental conditions that prevent organisms from dispersing (ie dispersal barriers) have far-reaching consequences for the organization of life on Earth. Dispersal barriers promote diversification and limit the distribution of populations and/or species (Holt et al. 2013). Yet, because dispersal barriers are rarely addressed

\section{In a nutshell:}

- Dispersal barriers drive many important ecological processes (eg population viability, speciation)

- Such barriers are dynamic features that can vary in strength and location, and can be affected by human intervention and environmental variation; however, they are rarely taken into account explicitly in global change studies

- It is important to be able to predict where they will appear or disappear, to consider their impact on species' distributions and gene flow, and to manage species or landscapes to mitigate their impacts

- Management options that account for population genetics need to be developed to help maintain the adaptive capacity of species when barriers disappear

${ }^{1}$ Centre for Environmental and Climate Change Research, Lund University, Lund, Sweden *(paul.caplat@gmail.com); ${ }^{2}$ Department of Molecular Biology 8 Biochemical Engineering, University Pablo de Olavide, Seville, Spain; ${ }^{3}$ Department of Biological Sciences, Macquarie University, Sydney, Australia; ${ }^{4}$ Department of Wetland Ecology, Estación Biológica de Doñana CSIC, Seville, Spain; ${ }^{5}$ Life Sciences Department, Natural History Museum, London, UK; ${ }^{6}$ Centre National de la Recherche Scientifique (CNRS) Unités Mixtes de Recherche (UMR) 5174, Laboratoire Evolution et Diversité Biologique (EDB), Toulouse, France; ${ }^{7}$ EDB, Université de Toulouse UPS, Toulouse, France; continued on last page explicitly in biogeographical models (Engler et al. 2012), our ability to accurately forecast the future of biodiversity is impeded.

In the context of rapid global environmental change, dispersal barriers can affect ecosystems through variations in their strength or location. Human-induced habitat fragmentation creates novel dispersal barriers, leading to decreasing population sizes, decreased species richness, and altered ecosystem functions (Haddad et al. 2015). Humans also circumvent or remove natural dispersal barriers by promoting the spread of species via deliberate and inadvertent introductions (Hulme et al. 2008) and changes in land use. Finally, the multiple effects of climate change (eg warming and acidification of oceans, changes in wind currents) create opportunities for dispersal barriers to rise or fall (Sorte 2013). The consequences of global change on the dynamics of dispersal barriers are therefore difficult to predict, especially as many of these mechanisms can have synergistic or antagonistic effects.

Although many studies have reviewed the causes and consequences of dispersal limitation (eg Ronce 2007; Travis et al. 2013), few have specifically considered the dynamics created by dispersal barriers themselves. Here we review recent literature on the ecological and evolutionary aspects of dispersal to highlight key elements of dispersal barrier dynamics in the face of global change (see WebReferences for the complete list of identified references). After defining dispersal barriers, we develop our synthesis into three points (Figure 1): (1) identifying barriers most susceptible to change, (2) predicting species' responses, and (3) designing species or ecosystem management efforts to increase or reduce connectivity, and to maintain adaptive potential; note that 


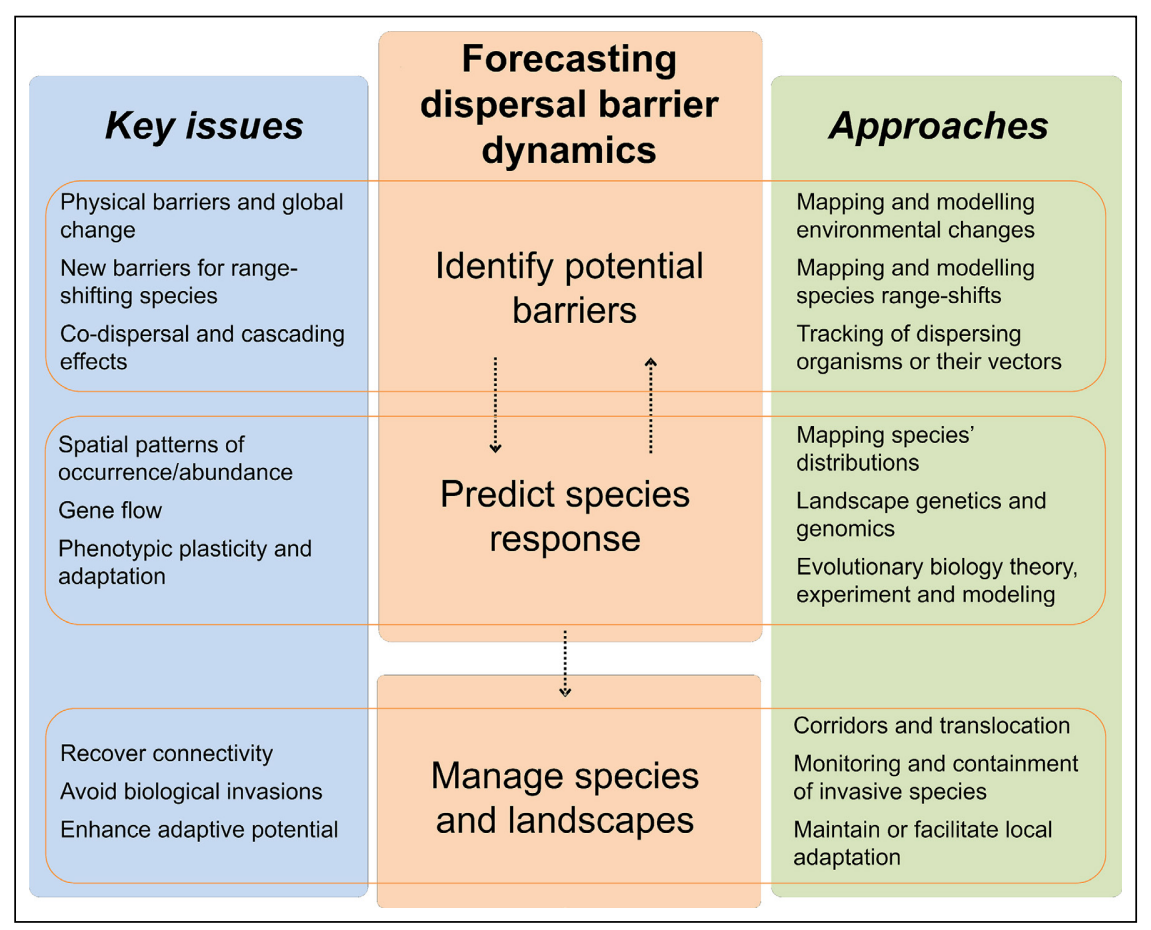

Figure 1. Studying dispersal barriers in a changing world.

topics (1) and (2) serve as a basis to develop a framework aimed at understanding the dynamics of dispersal barriers per se.

\section{Defining dispersal barriers}

Dispersal barriers have to be defined functionally (Dennis et al. 2013): a dispersal barrier is any environmental feature that limits movement through space, and whose effects depend on the interaction with species- or individualspecific traits. For instance, dispersal barriers include oceans for terrestrial species (Holt et al. 2013; Burrows et al. 2014) but can also be caused by high densities of conspecifics limiting immigration (De Meester et al. 2002).

To capture the full complexity of dispersal barriers, scientists must consider two aspects. First, dispersal can be seen as a three-stage process involving the departure of organisms from a natal or previous breeding site, a subsequent transience stage, and finally settlement at a new potential breeding site (Ronce 2007). Dispersal barriers can come into play at any of these stages (Dennis et al. 2013), though they are usually regarded as obstacles during the transience stage (eg a mountain between adjacent valleys).

Second, barriers are not binary, permanent obstacles, but rather are dynamic features that can vary in strength (recently illustrated in a proposal to extend the theory of island biogeography to account for surrounding habitat in man-made landscapes; Mendenhall et al. 2014) and extent whenever the environment changes (Zeigler and Fagan 2014), species evolve, or individuals adapt.
As such, barriers can be affected by human intervention and by climate. In the following sections we emphasize how dispersal barriers (to departure, transfer, and settlement) may appear or disappear as a result of global change, and how species respond to dispersal barriers. Bringing together these two topics allows us to consider how the dynamics of dispersal barriers can be approached. Even though barriers to dispersal may also affect other types of movement, such as seasonal migration or daily foraging, these are beyond the scope of this review.

\section{Falling and rising barriers}

Here we explore how the different components of global change may contribute to barrier dynamics either directly, or indirectly, by influencing dispersal vectors or range shifts.

\section{Dynamics of physical barriers as a consequence of global change}

Habitat fragmentation caused by land-use change is a well-documented mechanism by which dispersal barriers arise. Terrestrial systems have been particularly well studied, and deforestation (Haddad et al. 2015), road construction (Figure 2a; van der Grift and van der Ree 2015), urbanization, and other forms of habitat fragmentation cause major dispersal limitations (Baguette et al. 2013). Human regulation of freshwater flows and flooding patterns also has consequences for dispersal of aquatic organisms (Ozinga et al. 2009).

Human activities can directly facilitate dispersal and, consequently, remove barriers for other species. Biological invasions are frequently caused by human activities that reduce or remove dispersal barriers, or that elicit direct physical changes in the environment (Hulme et al. 2008). The introduction and subsequent removal of river dams create and destroy barriers for aquatic organisms (Branco et al. 2014). The construction of the Suez Canal enabled colonization of the Mediterranean Sea by many Red Sea species via a short-circuiting of a previously extensive oceanic barrier (Galil 2007). More often, though, it is the direct and deliberate (eg for biological control or trade) or inadvertent (eg via ship ballast water, air traffic) introduction of species that result in human-facilitated changes in species' dispersal barriers (see Hulme et al. 2008 for a review of invasion pathways).

Because many organisms rely on air and water flows for dispersal, any changes in climate have potentially large consequences for dispersal by wind and water 

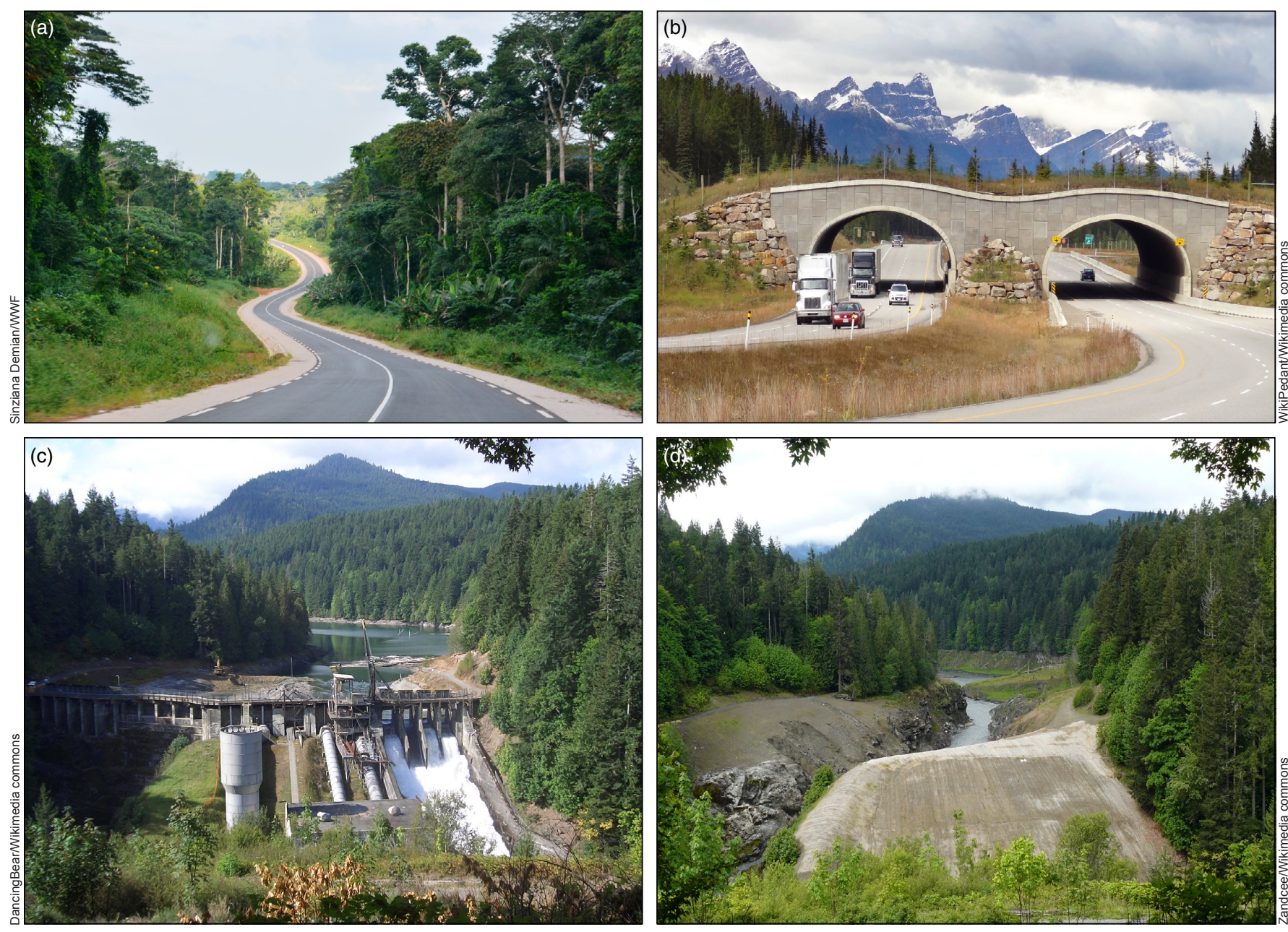

Figure 2. Examples of dynamic barriers and associated management options. Road building (a) is a ubiquitous example of dispersal barriers threatening biodiversity, particularly in tropical forests as illustrated by this recent highway, constructed in the heart of the Congo Basin rainforest. Wildlife crossings $(b)$ and other corridors are often proposed to recover connectivity between habitat areas. In Canada, the Elwha River dam (c), which negatively affected ecological processes (including fish dispersal), was removed in 2011 (d).

(see review by Sorte 2013). In particular, long-distance airborne introduction of new species can be determined by unusual weather events, such as strong winds (de la Giroday et al. 2012). Climate affects water movement and therefore barriers to dispersal in aquatic ecosystems, both vertically (eg via stratification) and horizontally (eg currents, eddies, fronts). Retreating glaciers and melting sea-ice open new habitats and dispersal pathways, by removing barriers that are acting at the transience or settlement stages (Clarke et al. 2005).

\section{Barriers emerging from distributional shifts}

As species' distributions shift following environmental change, new dispersal barriers are likely to appear, such as those that shape species' range limits (Anderson et al. 2009). These barriers may prevent organisms from tracking environmental changes sufficiently quickly selection to ensure survival. Delimiting a species' climatic niche and calculating climate trajectories are powerful ways to identify this type of barrier (Burrows et al. 2014). Some barriers can be easily inferred, such as large water bodies for terrestrial species ("coastal sinks" in Burrows et al. 2014). Other barriers can be deduced from information about geomorphology, land cover, or marine currents, though complementary methods are often needed (see "Detecting the impact of barriers on dispersal patterns" section below).

\section{Co-dispersal}

Dispersal of many species depends on the movement of others. Modification of dispersal pathways for species that respond to global change may therefore have cascading effects on other species that would not necessarily be affected otherwise. For instance, global change is having a radical effect on avian migration routes (eg Visser et al. 2009), which in turn will affect the dispersal of numerous organisms that rely on migrating 
birds as vectors for passive dispersal. Similarly, propagules dispersed by amphibians or fish between distant wetland sites are more likely to exhibit dispersal limitation than those dispersed by water birds (Viana et al. 2013), since amphibians and fish are generally more dispersal-limited. Given the current pace of extinctions, many species are losing their dispersal vectors (eg plants that rely on animals for dispersing pollen or seeds; Dirzo et al. 2014).

\section{Species' responses}

To gain insights into how species may respond to barrier dynamics, researchers must determine the effects of rising and falling barriers on dispersal potential. We suggest two steps: (1) using patterns of dispersal limitation to predict responses to changing barriers, and (2) assessing how plasticity and selection may change species' responses to barriers.

\section{Detecting the impact of barriers on dispersal patterns}

Heterogeneity in species' distributions over time and space has provided various opportunities for characterizing dispersal limitations. Barriers are usually assumed to occur when a species is absent from a similar, contiguous area offering suitable habitat (eg Naka et al. 2012). For instance, analyses of plant population trends suggest that important barriers to dispersal have been created in Europe owing to the loss of dispersal mechanisms for some plants, such as natural flooding regimes and mass movements of large mammals (Ozinga et al. 2009). Dispersal barriers may also be revealed when the spatial distribution of intraspecific phylogenetic lineages can be linked to past climatic changes (Peterson and Nyári 2008).

Geographic information system (GIS)-modeling can help to identify barriers when resistance of specific habitats to movement is known (McRae et al. 2012). But predicting how species respond to dispersal barriers - based on species' distributions - is complicated because doing so requires extensive mapping, correctly interpreting what "suitable habitat" or movement costs are (Zeller et al. 2012), and knowing about dispersal distances and dynamics. For example, areas of high population density may themselves represent barriers for immigrants of ecologically equivalent competitive species (Urban and De Meester 2009). Densitydependent dispersal complicates inferring dispersal barriers solely from distribution data, and we anticipate that future advances in this field of study may stem from improvements in dispersal modeling (through, for instance, individual-based models; McRae et al. 2012) and molecular ecology, as movement and genetic data become more readily available.
Detecting dispersal barriers by identifying their effects on genetic structure is a key objective of landscape genetics (Blair et al. 2012; Baguette et al. 2013). A major challenge for this approach is to distinguish genetic barriers from the effects of genetic isolation by distance. Existing methods are able to detect genetic barriers to movement (eg linear barriers; Blair et al. 2012), such as rivers, roads, dams, or mountains (eg Dudaniec et al. 2012). These are examples of symmetric barriers: they constrain dispersal in both directions. However, asymmetric genetic barriers also occur and may be common among organisms dispersed by abiotic means, such as by oceanographic circulation (eg Pringle et al. 2011), currents of lotic systems (Pollux et al. 2009), or wind. Biotic drivers of asymmetrical gene flow may include priority or monopolization effects (eg where order of arrival of individuals or species in a new area has a long-term impact on genetic structures; De Meester et al. 2002). Though rarely used in the context of barrier detection, asymmetric gene flow can be detected with methods that estimate population-specific backward migration rates (reviewed in Broquet and Petit 2009). The detection of barrier dynamics is further confounded by the temporal lag between ecological processes and population genetic structure (Landguth et al. 2010). Such temporal mismatches can be avoided by using genetic methods that allow tracking dispersal events in real time (Broquet and Petit 2009).

Finally, because any rising or falling barrier is likely to affect numerous species, multi-species approaches are preferred when characterizing connectivity (Breckheimer et al. 2014), and landscape genetic approaches are highly amenable to this (Whiteley et al. 2014). The ability to sample assemblages and to characterize and assess signatures of local adaptation by high-throughput sequencing approaches will improve our understanding of how genetic barriers are formed (Rellstab et al. 2015). Distinguishing genetic barriers created by the landscape or by behavioral, life-history, or adaptive processes is a formidable challenge. Improvements in the understanding of dispersal limitations will obviously help to construct better predictive models of barrier dynamics.

\section{Evolutionary changes in species' response}

Any aspect of dispersal (probability, success, direction, distance) can be seen as the product of the interaction of a disperser's traits and its environment (Clobert et al. 2009). Figure 3 illustrates how this interaction creates barriers and affects population dynamics. Traits vary between or within species, such that a barrier for one species or individual may not constitute a barrier for another species or individual of the same species (Clobert et al. 2009; Travis et al. 2013). These traits are not fixed, however, as organisms can react through 
plastic and/or selection processes to developing or disappearing barriers.

Evolutionary responses to barriers can develop in two different directions. On the one hand, when the probability of crossing the barrier is close to zero, strong selection against dispersing individuals and subsequent reduction in dispersal propensity is expected, and has been documented in the case of severe fragmentation (Bonte et al. 2006). On the other hand, when crossing the barrier is possible and confers higher fitness, dispersal is selected for and can be expected to increase; this has been recognized in the case of climate change (Thomas et al. 2001) and invasions (Phillips et al. 2006) with selection for increased dispersal rate resulting in rapid colonization of newly available habitat (see also Travis et al. 2013).

In general, if individuals vary genetically in their ability to cross a dispersal barrier, it should result in non-random gene flow from one side of the barrier to the other

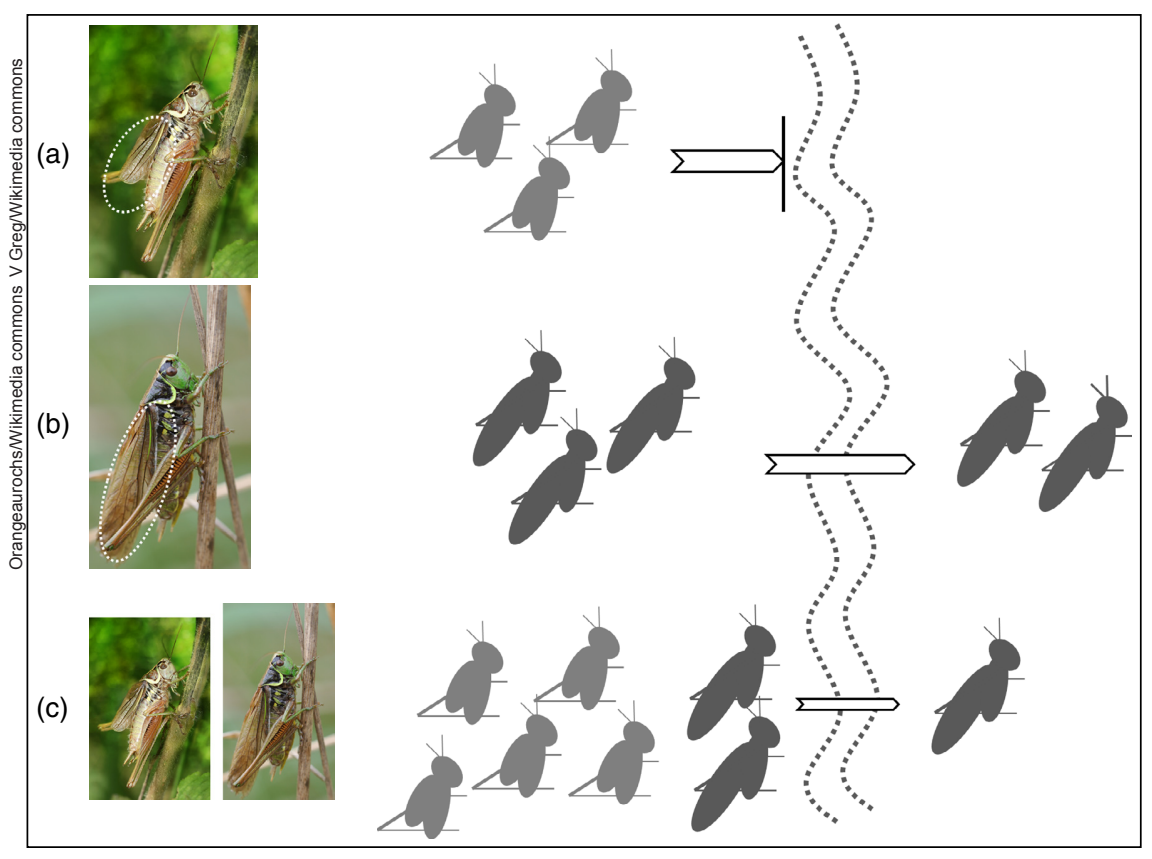

Figure 3. Dispersal barriers are a result of the interaction between dispersers' traits and the environment. Wing dimorphism in Roesel's bush cricket (Metrioptera roeselii) demonstrates that environmental features that act as a dispersal barrier to short-winged individuals (a) may not act as a barrier to long-winged individuals (b). The frequency of these two phenotypes varies as the selection pressure for dispersal capacity changes (c) (Thomas et al. 2001), and local adaptation occurs on each side of the barrier.
(Edelaar and Bolnick 2012). This outcome will decrease genetic diversity among dispersers but might facilitate the colonization of novel habitats by specific individuals displaying a phenotypic disperser or colonizer behavioral syndrome (Clobert et al. 2009). In such syndromes, phenotypic and life-history traits that improve the ability to disperse and/or to settle in previously unoccupied habitats can be genetically correlated with dispersal behavior (Cote et al. 2010). Taken together, plastic and evolutionary responses to changes in dispersal barriers imply that today's dispersal rates and distances may be different from those of tomorrow.

\section{Forecasting barrier dynamics}

Anthropogenic global change and its effects on range distributions and dispersal vectors increase the pace at which dispersal barriers may change. Because dispersal barriers have such profound effects on the species' distributions, the probability that they will persist, and their adaptive potential, tools need to be developed that help forecast where those barriers will rise or fall. This requires combining global change scenarios with likely species' responses. In addition, given that barriers usually affect entire communities, multi-species approaches will likely be needed to effectively forecast the impacts of these barriers, despite the difficulties associated with community-level modeling. Exploring dispersal strategies with spatially explicit individual-based models has already proven useful in recovering known dispersal barriers at a regional scale in the Pacific Ocean (Treml et al. 2015). Dispersal traits were not allowed to evolve in this study, which focused on passively dispersed species. The route taken in the modeling of spatial distribution shifts under global change (eg Bocedi et al. 2014) shows how dispersal evolution can be taken into account, although such approaches are so far limited to single, actively dispersing species. A combination of functional grouping of species, spatially explicit modeling, dispersal trait evolution, and global change scenarios could serve as a basis for future developments (Marcot et al. 2015).

\section{Management options}

Notably, most recommendations for managing biodiversity under climate change concern dispersal barrier mitigation (see Table 1 in Heller and Zavaleta 2009). The eco-evolutionary consequences of changing dispersal barriers are numerous, and can be understood directly by looking at the consequences of dispersal limitation (see Edelaar and Bolnick 2012; Baguette et al. 2013). Although evaluating every possible effect of rising or 
falling barriers on populations and species might be overwhelming, one thing is obvious: removing or maintaining/creating barriers are two management options that should be considered, with the ultimate choice depending on context and management goals (Hermoso et al. 2015).

\section{Mitigating the effects of dispersal barriers: recovering connectivity}

Management goals often involve alleviating the effects of a developing barrier; this may be achieved by enabling source populations to increase emigration rates, creating dispersal corridors, moving target species (translocation or assisted migration), or removing barriers. Corridors help increase connectivity (Hale et al. 2001; Gilbert-Norton et al. 2010) and have therefore been used extensively, particularly in counteracting the negative effects of roads (wildlife crossings; Figure 2b; van der Grift and van der Ree 2015). However, their efficacy depends on their implementation, and speciesspecific assessments are still needed (van der Grift and van der Ree 2015). Translocations may be the only viable alternative for managing isolated populations, but they are difficult to implement and may increase biological invasion risk; as a consequence, they are still highly controversial (Webber et al. 2011). Barrier destruction has become an option when the barrier is of anthropogenic origin and when the potential for restoring connectivity is well understood, as in the case of river dams (Figure 2, $\mathrm{c}$ and d). Yet the number of dams is so high that removals need to be prioritized based on ecological and economic constraints (Branco et al. 2014).

\section{When barriers disappear: what about adaptive potential?}

Management of the results of disappearing barriers has concentrated on controlling invasive species. Invasion biology is a vast discipline that aims to produce management options through the modification of landscapes or by controlling invasion pathways (Hulme et al. 2008; Caplat et al. 2012). Maintaining or even creating new barriers can have additional benefits, such as preventing disease spread or hybridization between native and introduced species or strains (Hermoso et al. 2015). Adaptive potential, which is often presented as a key objective for climate-change adaptation (IPCC 2014), has been overlooked as a basis for management guidelines. We are not aware of any research focused on conserving population genetic structure when dispersal barriers are removed. What strategies could be developed to maintain or improve the capacity of species to track climate? In light of the rapid adaptation exhibited by range-shifting species (see "Evolutionary changes in species' response" section above), it is worth considering that barriers could increase the selection toward dispersers and thereby increase the potential for range shifting. The genetic tools developed in the past decade, the recent interest in dispersal syndromes (Baguette et al. 2013), and research on managing micro-evolution (eg Rice and Emery 2003) are likely to improve our understanding of the role of dispersal barriers for adaptive potential.

\section{Conclusions}

Dispersal barriers have important consequences for population dynamics and genetics, species' distributions, and community composition, and therefore should be a key focus in evolutionary and conservation biology and biogeography. Here we have outlined the motivational and conceptual means to identify where changes in dispersal barrier strengths and locations are likely to occur. Clearly, the interacting roles of extrinsic (environmental) and intrinsic (organismal) characteristics are mutually influential in defining the properties of a dispersal barrier. Both extrinsic and intrinsic characteristics may also alter under global change, causing the development or disappearance of dispersal barriers in different ways for different species.

This overview is intended to promote future research to identify, understand, predict, and manage the dynamics of dispersal barriers. We suggest a sequence of research objectives that should improve our capacity to predict the effects of global change, based on (1) identifying emerging or disappearing barriers, (2) predicting the response of species, and (3) choosing the appropriate mitigation strategy. Of these, the last is the most challenging, as it requires including knowledge on physical landscapes, species dispersal, and if possible, gene flow, in land management plans. In addition, the interaction between landscape features and species characteristics means that there will be no "one-size-fits-all" management approach, and only concerted efforts across taxa, biomes, and borders will provide the knowledge to manage dispersal barriers for conservation purposes and to maintain ecosystem function.

\section{Acknowledgements}

The ideas behind this paper stemmed from a symposium held at Lund University, Sweden, in January 2013, supported by the BECC (Biodiversity and Ecosystem Services in a Changing Climate) research environment and the Centre for Animal Movement Research (CAnMove). We thank W Vyverman and P Bentzen for discussions that led to this paper, and $\mathrm{T}$ Broquet for comments on an early draft. 


\section{References}

Anderson BJ, Akçakaya HR, Araújo MB, et al. 2009. Dynamics of range margins for metapopulations under climate change. Proc R Soc B 276; doi:10.1098/rspb.2008.1681.

Baguette M, Blanchet S, Legrand D, et al. 2013. Individual dispersal, landscape connectivity and ecological networks. Biol Rev 88: 310-26.

Blair C, Weigel DE, Balazik M, et al. 2012. A simulation-based evaluation of methods for inferring linear barriers to gene flow. Molecular Ecol Resour 12: 822-33.

Bocedi G, Palmer SCF, Pe'er G, et al. 2014. RangeShifter: a platform for modelling spatial eco-evolutionary dynamics and species' responses to environmental changes. Methods Ecol Evol 5: 388-96.

Bonte D, Vanden Borre J, Lens L, et al. 2006. Geographical variation in wolf spider dispersal behaviour is related to landscape structure. Anim Behav 72: 655-62.

Branco P, Segurado P, Santos JM, et al. 2014. Prioritizing barrier removal to improve functional connectivity of rivers. J Appl Ecol 51: 1197-206.

Breckheimer I, Haddad NM, Morris WF, et al. 2014. Defining and evaluating the umbrella species concept for conserving and restoring landscape connectivity. Conserv Biol 28: 1584-93.

Broquet T and Petit EJ. 2009. Molecular estimation of dispersal for ecology and population genetics. Annu Rev Ecol Evol Syst 40: 193-216.

Burrows MT, Schoeman DS, Richardson AJ, et al. 2014. Geographical limits to species-range shifts are suggested by climate velocity. Nature 507: 492-95.

Caplat P, Coutts S, and Buckley YM. 2012. Modeling population dynamics, landscape structure, and management decisions for controlling the spread of invasive plants. Ann NY Acad Sci 1249: 72-83.

Clarke A, Barnes DKA, and Hodgson DA. 2005. How isolated is Antarctica? Trends Ecol Evol 20: 1-3.

Clobert J, Le Galliard JF, Cote J, et al. 2009. Informed dispersal, heterogeneity in animal dispersal syndromes and the dynamics of spatially structured populations. Ecol Lett 12: 197-209.

Cote J, Clobert J, Brodin T, et al. 2010. Personality-dependent dispersal: characterization, ontogeny and consequences for spatially structured populations. Philos Trans Roy Soc Lond Ser B: Biol Sci 365: 4065-76.

de la Giroday H-MC, Carroll AL, and Aukema BH. 2012. Breach of the northern Rocky Mountain geoclimatic barrier: initiation of range expansion by the mountain pine beetle. J Biogeogr 39: 1112-23.

De Meester L, Gómez A, Okamura B, et al. 2002. The Monopolization Hypothesis and the dispersal-gene flow paradox in aquatic organisms. Acta Oecol 23: 121-35.

Dennis RH, Dapporto L, Dover J, et al. 2013. Corridors and barriers in biodiversity conservation: a novel resource-based habitat perspective for butterflies. Biodivers Conserv 22: 2709-34.

Dirzo R, Young HS, Galetti M, et al. 2014. Defaunation in the Anthropocene. Science 345: 401-06.

Dudaniec RY, Spear SF, Richardson JS, et al. 2012. Current and historical drivers of landscape genetic structure differ in core and peripheral salamander populations. PLoS ONE 7: e36769.

Edelaar P and Bolnick DI. 2012. Non-random gene flow: an underappreciated force in evolution and ecology. Trends Ecol Evol 27: 659-65.

Engler R, Hordijk W, and Guisan A. 2012. The MIGCLIM R package - seamless integration of dispersal constraints into projections of species distribution models. Ecography 35: 872-78.
Galil BS. 2007. Loss or gain? Invasive aliens and biodiversity in the Mediterranean Sea. Mar Pollut Bull 55: 314-22.

Gilbert-Norton L, Wilson R, Stevens JR, et al. 2010. A metaanalytic review of corridor effectiveness. Conserv Biol 24: 660-68.

Haddad NM, Brudvig LA, Clobert J, et al. 2015. Habitat fragmentation and its lasting impact on Earth's ecosystems. Science Advances 1: e1500052.

Hale ML, Lurz PWW, Shirley MDF, et al. 2001. Impact of landscape management on the genetic structure of red squirrel populations. Science 293: 2246-48.

Heller NE and Zavaleta ES. 2009. Biodiversity management in the face of climate change: a review of 22 years of recommendations. Biol Conserv 142: 14-32.

Hermoso V, Januchowski-Hartley SR, and Linke S. 2015. Systematic planning of disconnection to enhance conservation success in a modified world. Sci Total Environ 536: 1038-44.

Holt BG, Lessard JP, Borregaard MK, et al. 2013. An update of Wallace's zoogeographic regions of the world. Science 339: 74-78.

Hulme PE, Bacher S, Kenis M, et al. 2008. Grasping at the routes of biological invasions: a framework for integrating pathways into policy. J Appl Ecol 45: 403-14.

IPCC (Intergovernmental Panel on Climate Change). 2014. Climate change 2014: impacts, adaptation, and vulnerability. Part B: regional aspects. Contribution of Working Group II to the Fifth Assessment Report of the Intergovernmental Panel on Climate Change [Barros VR, Field CB, Dokken DJ, et al. (Eds)]. Cambridge, UK, and New York, NY: Cambridge University Press.

Landguth EL, Cushman SA, Schwartz MK, et al. 2010. Quantifying the lag time to detect barriers in landscape genetics. Mol Ecol 19: 4179-91.

Marcot BG, Singleton PH, and Schumaker NH. 2015. Analysis of sensitivity and uncertainty in an individual-based model of a threatened wildlife species. Nat Resour Model 28: $37-58$.

McRae BH, Hall S, Beier P, et al. 2012. Where to restore ecological connectivity? Detecting barriers and quantifying restoration benefits. PLoS ONE 7: e52604.

Mendenhall CD, Karp DS, Meyer CFJ, et al. 2014. Predicting biodiversity change and averting collapse in agricultural landscapes. Nature 509: 213-17.

Naka LN, Bechtoldt CL, Magalli Pinto Henriques L, et al. 2012. The role of physical barriers in the location of avian suture zones in the Guiana Shield, Northern Amazonia. Am Nat 179: E115-E132.

Ozinga WA, Roemermann C, Bekker RM, et al. 2009. Dispersal failure contributes to plant losses in NW Europe. Ecol Lett 12: $66-74$.

Peterson AT and Nyári ÁS. 2008. Ecological niche conservatism and Pleistocene refugia in the thrush-like mourner, Schiffornis $\mathrm{sp}$, in the neotropics. Evolution 62: 173-83.

Phillips BL, Brown GP, Webb JK, et al. 2006. Invasion and the evolution of speed in toads. Nature 439: 803.

Pollux BJA, Luteijn A, Van Groenendael JM, et al. 2009. Gene flow and genetic structure of the aquatic macrophyte Sparganium emersum in a linear unidirectional river. Freshwat Biol 54: 64-76.

Pringle JM, Blakeslee AMH, Byers JE, et al. 2011. Asymmetric dispersal allows an upstream region to control population structure throughout a species' range. P Natl Acad Sci USA 108: 15288-93.

Rellstab C, Gugerli F, Eckert AJ, et al. 2015. A practical guide to environmental association analysis in landscape genomics. Mol Ecol 24: 4348-70. 
Rice KJ and Emery NC. 2003. Managing microevolution: restoration in the face of global change. Front Ecol Environ 1: 469-78.

Ronce O. 2007. How does it feel to be like a rolling stone? Ten questions about dispersal evolution. Annu Rev Ecol Evol Syst 38: 231-53.

Sorte CJB. 2013. Predicting persistence in a changing climate: flow direction and limitations to redistribution. Oikos 122: 161-70.

Thomas CD, Bodsworth EJ, Wilson RJ, et al. 2001. Ecological and evolutionary processes at expanding range margins. Nature 411: $577-81$.

Travis JMJ, Delgado M, Bocedi G, et al. 2013. Dispersal and species' responses to climate change. Oikos 122: 1532-40.

Treml E, Roberts J, Halpin P, et al. 2015. The emergent geography of biophysical dispersal barriers across the Indo-West Pacific. Divers Distrib 21: 465-76.

Urban MC and De Meester L. 2009. Community monopolization: local adaptation enhances priority effects in an evolving metacommunity. Proc $R$ Soc B 276: 4129-38.

van der Grift EA and van der Ree R. 2015. Guidelines for evaluating use of wildlife crossing structures. In: van der Ree R, Smith DJ, and Grilo C (Eds). Handbook of road ecology. Chichester, UK: John Wiley \& Sons.

Viana DS, Santamaría L, Michot TC, et al. 2013. Migratory strategies of waterbirds shape the continental-scale dispersal of aquatic organisms. Ecography 36: 430-38.

Visser ME, Perdeck AC, van Balen JH, et al. 2009. Climate change leads to decreasing bird migration distances. Global Change Biol 15: 1859-65.
Webber BL, Scott JK, and Didham RK. 2011. Translocation or bust! A new acclimatization agenda for the 21st century? Trends Ecol Evol 26: 495-96.

Whiteley A, McGarigal K, and Schwartz M. 2014. Pronounced differences in genetic structure despite overall ecological similarity for two Ambystoma salamanders in the same landscape. Conserv Genet 15: 573-91.

Zeigler SL and Fagan WF. 2014. Transient windows for connectivity in a changing world. Movement Ecol 2; doi:10.1186/2051-3933-2-1.

Zeller K, McGarigal K, and Whiteley A. 2012. Estimating landscape resistance to movement: a review. Landscape Ecol 27: 777-97.

\section{Supporting Information}

Additional, web-only material may be found in the online version of this article at http://onlinelibrary. wiley.com/doi/10.1002/fee.1280/suppinfo

${ }^{8}$ Department of Biology Eु Environmental Sciences, University of Gothenburg, Tjärnö Marine Biological Laboratory, Strömstad, Sweden; ${ }^{9}$ Department of Design Sciences, Lund University, Lund, Sweden; ${ }^{10}$ Department of Marine Sciences, University of Gothenburg, Gothenburg, Sweden; ${ }^{11}$ L'Institut National de la Recherche Agronomique (INRA)/Agrocampus Ouest, UMR Ecologie et Santé des Ecosystèmes, Rennes, France; 'these authors contributed equally to this work 